\title{
Е.В. Белоглазова
}

Санкт-Петербургский государственный университет экономики и финансов

\section{Полидискурсность как адресато-обусловленная характеристика текста}

Аннотащия: Данная статья посвящена раскрытию нового для лингвистики понятия полидискурсности, под которой понимается регулярный идеологически обусловленный набор дискурсов, воспроизводимый в текстах определенной общности. Полидискурсность является фактором сложности при восприятии текста читателем, соответственно, автор должен принимать во внимание особенности своего адресата, его способности по декодировании текста. Стремление к минимизации сложности и оптимизации восприятия текста приводит к преимущественной монодискурсности текстов для начинающих читателей, младших дошкольников. По мене взросления адресата нарастает и дискурсная гетерогенность художественной литературы.

The present article deals with a new linguistic concept of polydiscoursivity, representing a regular ideologically conditioned set of special discourses reproduced in a certain textual massive. The fact that polydiscoursivity is a complexity factor by the text reception accounts for its being determined by the text addressee parameters: the author has to keep the text complexity within the ideal reader decoding abilities. Thus the texts for the youngest readers tend to be monodisoursive, while discoursive heterogeneity increases as the reader gains age and experience.

Ключевые слова: полидискурс, интердискурс, диалогичность, когнитивная структура, детская художественная литература.

Polydiscourse, interdiscourse, dialogue, cognitive structure, children's fiction.

УДК: 81-42; 82-3-087.5.

Контактная информация: Санкт-Петербург, ул. Садовая, 21. СПбГУЭФ, кафедра теории языка и переводоведения. Тел. (812) 3105160. E-mail: raemahet@rambler.ru.

\section{К определению полидискурсности}

Проблема, вынесенная в заголовок, рассматривается нами на материале англоязычной детской художественной литературы. В настоящей статье мы продолжаем рассуждения, начатые в наших предшествующих публикациях [Белоглазова, 2006, с. 206-215; 2007, с. 92-105], в которых фокусируется новое для лингвистики понятие - полидискурсность.

Полидискурсность видится нам как переплетение различных дискурсов в единый социокультурно-обусловленный полидискурс, воспроизводящий себя в открытом множестве текстов, объединенных общей сферой применения и специфичной идеологией. Поскольку полидискурсность представляется как диалог на уровне дискурсов, важно предварительно прояснить отношение между полидискурсностю и интердискусностью.

Понятие интердискурса существует столько же, сколько и дискурсный анализ, в его французской ипостаси. Термин «интердискурс» принадлежит М. Пеше, 
понимавшему под ним «сложное целое» дискурсной формации и «комплекса идеологических формаций», скрывающихся за прозрачностью дискурса. Понятие интердискурса оказывается тесно связанным с понятием преконструкта - совокупности предшествующих дискурсов, выступающих как «сырье» для нового дискурса. Обусловленный преконструктом, любой дискурс является в то же время интердискурсом [Пеше, 1999, с. 266-270]. Как отмечает в своем обзоре истории французского анализа дискурса П. Серио, под влиянием Пеше в последующих работах дискурсные объекты рассматривались «под тройным напряжением: системности языка, историчности и интердискурсивности» [Серио, 1999, с. 34-35].

В современных исследованиях дискурс и интердискурс не отождествляются, но противопоставляются. Фактически, можно провести параллель между развитием теории интердискурсивности и теории интертекстуальности. Изначально заявленные радикально широко, они развивались в сторону сужения, при этом акцент смещался на поиск конкретных сигналов соответствующих диалогических отношений. Так на данном этапе развития теории дискурса под интердискурсивностью понимается «особая взаимосвязь языковых единиц (выделено нами. - E.Б.), которая и инициирует в воспринимающем сознании (т.е. в голове читателя) переход от одного типа дискурса и, значит, типа мышления, к другому с целью создания сильного воздействующего эффекта» [Чернявская, 2007, с. 23]. Усмотреть диалогические отношения можно между любыми произвольно взятыми явлениями, но если такой вывод не подкреплен конкретным текстовым материалом, сигнализирующем переключение с одного «ментального пространства» на другое, речь будет идти не об анализе, иначе говоря, интерпретации дискурса, а о сверхинтерпретации (“overinterpretation”) в терминах У. Эко [Щирова, Тураева, 2005].

Полидискурсность не подразумевает иного, отличного от интердискурсивности диалогического механизма. Различие между ними лежит в иной плоскости: интердискурсность фокусирует процесс взаимодействия дискурсов, в то время как для нас более релевантным оказывается акцент на результате этого процесса. Интердискурс спонтанен и индивидуален, характеризует каждый отдельный текст, в то время как о полидискурсе может идти речь лишь применительно к достаточно устойчивому набору специальных дискурсов, наличие которых характеризует сверхтекст ${ }^{1}$.

Детская художественная литература представляется очень иллюстративным материалом для исследования полидискурсности. Прежде всего, отметим, что дискурсная гетерогенность характеризует художественную литературу в целом. Разные авторы предлагали выделять и классифицировать дискурсы на основании различных критериев - темы (В.Е. Чернявская), концепта (В.З. Демьянков), социиального института (В.И. Карасик), сочиальных ролей участников коммуникации (А. МакХоул), сочиального пространства (Е.И. Шейгал), автора, понимаемого как «агент сочииального действия» (П.Б. Паршин) и др. Представляется, однако, различия здесь достаточно поверхностные, в то время как фактически все указанные критерии вполне соотносимы со «специфической социокультурной деятельностью», которой соответствуют «особый тип языкового употребления и особый тип текстов» [ван Дейк, 1989, с. 112], которые и составляют дискурс. Очевидно, что указанный критерий мало применим к анализу художественной литературы. Здесь мы готовы поспорить с точкой зрения, озвученной Д. Мэнгено. Выделяя несоставные (self-constituting) и составные (constituted) дискурсы, автор однозначно относит художественную литературу к первым, характеризующимся

1 «Сверхтекст - совокупность высказываний, текстов, ограниченная темпорально и локально, объединенная содержательно и ситуативно, характеризующаяся цельной модальной установкой, достаточно определенными позициями адресанта и адресата, особыми критериями нормального и анормального. Рассматриваемый сверхтекст обладает категориальной спецификой» [Купина, 1995, с. 53]. 
дискурсной чистотой и гомогенностью. Они не содержат инодискурсных элементов, но сами содержатся в других дискурсах: «ultimate discourses upon which others are based» [Maingueneau, 1999, p. 183-189]. С этим положением трудно согласиться, поскольку художественная литература никак не характеризуется несоставностью и первичностью. Напротив, это сложное разнородное образование, и даже в рамках одного произведения может оказаться затруднительным определить его дискурсную принадлежность. Художественная литература неизбежно выходит за рамки любого дискурса. Художественный дискурс это всегда интердискурс [Link, Link-Heer, 1990], строящийся на «взаимодействии между различными типами дискурса, интеграции, пересечении нескольких различных областей человеческого знания и практики» [Чернявская, 2004, с. 35].

Однако именно художественная литература для детей позволяет нам наглядно проиллюстрировать различие между интердискурностью и полидискурсностью. Так, в интердискурсном плане детская художественная литература включает в себя все дискурсы, присутствующие во всех художественных произведениях, ориентированных на детскую аудиторию. Таких дискурсов будет открытое множество, не подлежащее исчерпывающему описанию. Значит ли это, что все они непременно будут частью полидискурса детской художественной литературы? По-видимому, плодотворным в данном случае будет полевой подход к структурированию этого множества, в котором можно выделить ядерную и периферийную зоны. И лишь ядро этой структуры может быть названо собственно полидискурсом, поскольку периферийные компоненты не будут удовлетворять требованиям социокультурной обусловленности и стабильной воспроизводимости. Критерием же ядерности может служить идеологическая обусловленность того или иного дискурса [см.: Белоглазова, 2007, с. 92-105]. Из всего многообразия специальных дискурсов, представленных в текстах литературы для детей, в структуру полидискурса детской художественной литературы могут быть включены лишь те, что согласуются с критерием идеологии современной детской литературы; они группируются вокруг двух ее идеологических функций - социализации и развлечения адресата.

Также анализ литературы для детей позволяет нам показать оппозицию интердискурсности и полидискурсности в плане градуальности. Но, прежде чем обратиться к этой оппозиции, необходимо описать механизм диалогичности, лежащий в основе обоих явлений.

\section{Механизм диалогичности на уровне дискурса}

Понимание дискурса как формы хранения и представления знаний восходит еще к М. Фуко, о чем свидетельствует и название его труда, посвященного проблеме дискурса, - «Археология знания» [Фуко, 1996]. Назначение дискурса состоит в том, чтобы сделать возможным процессы приобретения, хранения, преобразования, порождения и применения человеком знаний. Т. ван Дейк описал механизм представления знания в дискурсе в терминах когнитивной лингвистики. Поступающий текст разлагается реципиентом на составные пропозиции, которые соотносятся в процессе осмысления со структурированными знаниями о внешнем мире (т.е. с «ментальными моделями») и знаниями о типах дискурса и особенностях их организации (т.е. «схематическими суперструктурами») [ван Дейк, 1989, c. 116-160].

Когнитивные структуры взаимосвязаны в мышлении, один и тот же концепт присутствует в разного вида структурах. Это закономерно приводит к трудности выбора искомой когнитивной структуры. Выбор должен базироваться на подсказках - сферах пересечения, совпадения конкретной ситуации с имеющимися в памяти репрезентациями опыта. При этом подсказки должны даваться в начале ини- 
циации процесса понимания, и быть достаточно однозначными, в противном случае понимание может запоздать или пойти по ложному пути.

Ментальные структуры вступают друг с другом в различные логические связи, объединяясь в ментальный коррелят той или иной сферы жизнедеятельности. Наличие связи между моделями, их принадлежность к общей области знаний обеспечивает когерентность и гомогенность воспринимаемого текста. Однако абсолютно гомогенный и связный текст - явление редкое. В реальности читателю приходится иметь дело с текстами разной степени несвязности, в которых связность может нарушаться, во-первых, отсутствием в памяти реципиента соответствующей тексту ментальной модели; и, во-вторых, вклиниванием в когнитивную структуру текста чуждых моделей, относящихся к другой сфере жизнедеятельности.

Реципиенту, столкнувшемуся с подобным нарушением связности на когнитивном уровне, приходится активировать в памяти иную ментальную сферу, к которой относится вызванная чужеродным элементом текста модель. Таким образом, в тексте соприсутствуют элементы различных дискурсов, выступающих языковыми коррелятами ментальных сфер.

Введение инодискурсных элементов, нарушающих когнитивную связность текста, является фактором сложности при восприятии текста читателем. И особенно если адресатом текста является неопытный читатель, как в случае детской литературы, такая дополнительная сложность должна быть оправдана. Соответственно, логично предположить зависимость степени интердискурсности произведения, как фактора сложности, от возраста его адресата, проявляющуюся в ее нарастании пропорционально взрослению читателя, которому предназначается произведение.

Т.е. интердискурсность представляется величиной непостоянной, индивидуальной для каждого произведения, демонстрируя тенденцию к нарастанию пропорционально изменению возраста идеального читателя. В то время как полидискурсность не характеризуется градуальностью. Качественный состав полидискурса неизменен и служит средством выражения определенной идеологии. Именно фактор идеологии, единой для всей литературы для детей, позволяет нам говорить о едином полидискурсе детской художественной литературы, не смотря на то, что она представляет собой достаточно разнообразный по жанровому, возрастному, гендерному и другим параметрам корпус текстов, демонстрирующих, помимо прочего, различия и в степени интердискурсности.

Чтобы не быть голословными, ниже мы проиллюстрируем наши рассуждения сравнением произведений, адресованных полярным возрастным группам, находящимся на нижней и верхней границах детского возраста. С одной стороны, мы рассмотрим дискурсный состав книг-картинок, предназначенных для самых маленьких, начинающих читателей; с другой стороны, - многотомный роман о Гарри Поттере, адресованный подростково-юношеской аудитории.

\section{Дискурсная структура литературы для дошкольной аудитории}

Книги-картинки характеризуются, прежде всего, повышенной креолизованностью. Наличие усиленного невербального компонента представляется характерной чертой детской литературы в целом. Связана эта черта с особой адресованностью литературы для детей, с учетом особенностей адресата-ребенка, а именно, преимущественно наглядно-образного типа его мышления. И, очевидно, максимальную степень ее проявления мы будем наблюдать в произведениях, обращенных к самым маленьким читателям.

На современном этапе развития детской художественной литературы художник-иллюстратор является соавтором книги, его имя указывается наравне с именем автора [Marcus, 2002]. Нередко автор и иллюстратор - один человек, реали- 
зующий свой художественный замысел в двух плоскостях - текстовой и визуальной - одновременно. Наиболее тесно вербальный и невербальный компоненты переплелись в особом типе детских книг - книгах-картинках (picture books). Причем эти два аспекта не просто соприсутствуют в книге, но тесно переплетаются, взаимно дополняют друг друга. Отношения между вербальным и невербальным рядами может варьироваться от простого дублирования до дополнения или, даже, контраста.

В некоторых работах креолизованность, «межсемиотичность» отождествляется с интедискурсностью [Горбунова, 2007, с. 85-92], т.е. дискурс оказывается связанным с определенной семиотической системой, а не фрагментом мира. Однако, нам ближе позиция, сформулированная Н.Д. Арутюновой в Лингвистическом Энциклопедическом Словаре, согласно которой «дискурс включает паралингвистическое сопровождение речи» [Арутюнова, 1990, с. 137], т.е. невербальный компонент произведения. Таким образом, в межсемиотичности детской художественной литературы, и книг-картинок в особенности, мы не усматриваем интердискурсности. Оба семиотических ряда содержательно взаимосвязаны и соотносимы с одной и той же ментальной сферой, которую они, каждый по своему, манифестируют. С точки зрения лингвистики и анализа дискурса невербальный компонент носит вспомогательный характер, помогая отождествить мир слов - собственно дискурс - и тот фрагмент действительности, вербализацией которого выступает этот дискурс.

Здесь мы вплотную подходим ко второй характерной черте рассматриваемого жанра - предельно узкая тематика. Книги-картинки призваны познакомить читателя с конкретным фрагментом действительности, который они стремятся представить в относительно полном и связном виде. Полнота представления относительна, поскольку на нее накладывает ограничения фактор идеологии детской художественной литературы - любое произведение должно реализовывать ключевые функции литературы для детей - социализации и развлечения, которые обусловливают как содержательный, так и формальный аспект произведений. Связность же трактуется преимущественно как когнитивная связанность, когерентность. Г.В. Колшанский так описывает это свойство текста: «интерпретатор считает текст с позиций некоторого лица дескриптивно когерентным, если он в состоянии поставить в соответствие этому тексту определенный коррелят, являющийся целостным с точки зрения этого лица. Коррелят понимается как фрагмент мира, который интерпретатор приписывает этому тексту» [Колшанский, 1990, с. 56-57]. Это определение оставляет возможность индивидуального восприятия текста в плане его связности, что делает любой текст относительно когерентным - относительно конкретного интерпретатора. Тем не менее, в случае книг-картинок мы имеем дело с максимально объективной когерентностью, поскольку идеальный читатель, адресат этих произведений не имеет еще собственного опыта в предметной сфере произведения, с которым он мог бы соотносить текст. А значит возможность индивидуальной интерпретации, а вместе с ней и роль второго участника коммуникации в формировании когерентности сводятся к минимуму.

Наши рассуждения строятся на анализе текстов из антологии The $20^{\text {th }}$ century children's book treasury («Сокровищница детских книг ХХ века»), в которой собраны лучшие книги-картинки для дошкольников. В качестве иллюстрации приведем рассказ Э.Дж. Китса The Snowy Day, адресованный по редакторской оценке средне-дошкольному возрасту, т.е. характеризующийся сюжетом и относительно развернутым вербальным компонентом, сильно подкрепленным визуальным рядом. Фрагмент мира, описываемый в данном произведении, очерчен в заглавии «Снежный день». Идеологическая направленность рассказа ясна - он призван показать ребенку, как можно получать удовольствие и от зимней прогулки. Прогул- 
ки важны для здоровья ребенка, а обществу важно вырастить своего нового члена здоровым, что и объясняет идеологическую подоплеку рассказа.

Весь рассказ цементируется общим сложным концептом зима, входящим в разворачивающуюся в произведении когнитивную структуру занимательная зимняя прогулка (акцент на положительные черты, порой необъективный, широко распространен в литературе для детей и также имеет идеологическую обусловленность). Рассматриваемая когнитивная структура имеет динамический характер и включает в себя последовательность действий:

- одевание в зимний комбинезон (snowsuit) и выход на улицу;

- хождение по снегу, включающее вслушивание в необычные звуки (Crunch, crunch, crunch, his feet sank into the snow) и оценку получившихся дорожек следов при смене стиля ходьбы (подкреплено звукоизобразительно и визуально изображением дорожек следов);

- обвал снега с дерева с помощью палки (подкреплено визуально и звукоизобразительно: Down fell the snow - plop! - on top of Peter's head);

- наблюдение за игрой старших детей в снежки (snowball fight), сопровождающееся здравым рассуждением персонажа о том, что сам он слишком мал еще для такой игры (подкреплено визуально);

- лепка улыбающегося снеговика (smiling snowman) (подкреплено визуальHO);

- создание на снегу следов-ангелов (подкреплено визуально);

- игра в скалолаза и катание с горки (подкреплено визуально);

- лепка снежка и принос его домой;

- снятие с помощью мамы мокрой одежды и рассказ о приключениях (подкреплено визуально);

- обнаружение растаявшего снежка.

В когнитивном плане рассказ оказывается объективно монолитным, создавая у читателя полноценный сценарий зимней прогулки, снабженный яркой позитивной оценкой. Т.е. можно заключить, что художественные произведения для младшей категории читателей отличает преимущественная монодискурсность и ярко выраженная идеологизированность выбора и подачи сведений о мире, призванных служить на начальном этапе заменой личному опыту.

\section{Дискурсная структура литературы для подростковой аудитории}

Совсем иную дискурсную структуру можно наблюдать в литературе, адресованной подростковой аудитории, именуемой в англоязычной традиции young adults (юные взрослые). Согласно автору серии романов о Гарри Потере, избранной нами в качестве иллюстрации, они предназначены детям от 8 лет. Но если это утверждение и можно принять для первого романа, то, в последующих книгах адресат взрослеет вместе с главными героями и 8-летнему читателю будут не близки, а то и попросту непонятны темы заключительных романов серии. Посему мы считаем, что это произведение уже не столько детской, сколько подростковой направленности, т.е. находится на противоположной от книг-картинок границе детской художественной литературы по возрастному параметру. Интердискурс романов Дж. Роулинг включает, во-первых, элементы дискурсов, носителями которых выступают волшебное и обывательское дискурсивные сообщества, а, вовторых, элементы специальных дискурсов, соотносимые с различными сферами деятельности в описываемом волшебном мире, создаваемые автором по моделям их аналогов в реальном мире. Так можно выделить учебный, научно-технический, природоведческий, медицинский, юридический, социологический, публицистический и другие дискурсы (более детальный анализ см.: [Белоглазова, 2006, с. 206215]). 
Очевидно, такая сложная когнитивная структура произведения требует обширного опыта читателя, его знаний, как устройства реального мира, так и различных дискурсивных практик, бытующих в нем, приобретение которых - долгий и трудоемкий процесс. Это подтверждает нашу гипотезу о возрастной обусловленности степени интердискурсности произведений литературы для детей.

\section{Заключение}

Подводя итог нашему рассуждению, мы хотим подчеркнуть следующее. Хотя в основе интердискурсности и полидискурсности лежит один механизм диалогичности на уровне дискурса, между ними не может быть поставлено знака равенства. Интердискурс спонтанен, а полидискурс - устойчив; интердискурс индивидуален для каждого текста, а полидискурс характеризует открытое множество текстов; интердискурс обусловлен конкретной коммуникативной ситуацией, а полидискурс обусловлен идеологией, объединяющей соответствующее множество текстов.

Анализ детской художественной литературы позволил нам наглядно продемонстрировать вариативность интердискурсов текстов, ориентированных на разновозрастную аудиторию. Дискурсы, входящие в эти интердискурсы, характеризуются разной степенью идеологической обусловленности, соответственно будет разниться и их положение в дискурсной структуре детской художественной литературы. И лишь центральные, ядерные дискурсы, чья облигаторность с точки зрения идеологии литературы для детей гарантирует их повторяемость и типичность, в литературе для детей в целом могут быть отнесены к полидискурсу детской художественной литературы.

\section{Литература}

Арутюнова Н.Д. Дискурс // Лингвистический энциклопедический словарь. M., 1990.

Белоглазова Е.В. Детская художественная литература в аспекте полидискурсивности // Стереотипность и творчество в тексте. Пермь, 2006.

Белоглазова Е.В. Роль идеологии в структурировании полидискурса детской художественной литературы // Лингвистика текста и дискурсивный анализ. СПб., 2007.

Горбунова Н.Г. Гетерогенность текста Дж. Джойса: о механизмах связности в «бессвязном» тексте // Лингвистика текста и дискурсивный анализ: Традиции и перспективы. СПб., 2007.

Дейк Т.А. ван. Анализ новостей как дискурса // Язык. Познание. Коммуникация. М., 1989.

Колшанский Г.В. Объективная картина мира в познании и языке. М., 1990.

Купина Н.А. Тоталитарный язык: словарь и речевые реакции. Екатеринбург; Пермь, 1995.

Пеше М. Прописные истины. Лингвистика, семантика, философия // Квадратура смысла: Французская школа анализа дискурса / Под ред. Ю.С. Степанова. M., 1999.

Серио П. Как читают тексты во Франции // Квадратура смысла: Французская школа анализа дискурса / Под ред. Ю.С. Степанова. М., 1999.

Фуко М. Археология знания. Киев, 1996.

Чернявская В.Е. Текст как интердискурсивное событие // Текст - Дискурс Стиль. СПб., 2004.

Чернявская В.Е. Открытый текст и открытый дискурс: интертекстуальность - дискурсивность - интердискурсивность // Стил-6. Белград, 2007. 
Щирова И.А., Тураева 3.Я. Текст и интерпретация: взгляды, концепции, школы. СПб., 2005.

Link J., Link-Heer U. Diskurs / Interdiskurs und Literaturanalyse // Zeitschrift fur Literaturwissenschaft und Linguistik 20. 1990.

Maingueneau D. Analyzing self-constituting discourses // Discourse studies, 1 (2). 1999.

Marcus L.S. Ways of Telling. N.Y., 2002. 